\title{
RISK PERCEPTION \\ RELATED TO CRITICAL INFRASTRUCTURE
}

\author{
Dorel BADEA* \\ dorel.badea@yahoo.com \\ Crenguța MACOVEI* \\ mihaela.macovei1@gmail.com \\ Olga Maria Cristina BUCOVEȚCHI** \\ olga.bucovetchi@upb.ro \\ Marian COMAN* \\ com.mary@yahoo.com \\ * "NICOLAE BĂLCESCU” LAND FORCES ACADEMY, SIBIU, ROMANIA \\ **UNIVERSITY POLITEHNICA OF BUCHAREST, ROMANIA
}

\begin{abstract}
Through this article it is brought to attention the essential aspects related to the perceived risks for critical infrastructure, both theoretically and practically, considering perception as an important input in the risk management process. For the practical part, the added value component in the field consists from the results of research based on survey, conducted in a wider framework of determining the level of awareness of the critical infrastructure issue by a pilot sample, consisting of persons with managerial and operational attributions in this sector.
\end{abstract}

\section{KEYWORDS:}

Risk, critical infrastructure, perception, survey

\section{Theoretical Considerations and Research Findings Milestones \\ The main reason for approach this topic derives both from the practical importance and the fact that there is no}

sufficient theoretical elaborations that could constitute milestones in the development of applied studies. Most of the research in the field of critical infrastructure in which are investigated risk and associated processes 
(vulnerability, threat) bring into attention the impact and likelihood of an unwanted event occurs, with implications for their functionality, focusing on quantitative analysis models. When there are investigated risks and individual behavior, there is a psychological direction of research compared to the classic one, most frequently tackled (technical and managerial), in which various theories were formulated. Very often quoted in the scientific literature is that elaborated by Rogers in 1975 (and revised in 1983) according which, people are more cautious and more willing to protect himself when anticipated negative consequences of risk, also when they want to avoid these consequences and they feel that are able to take preventive measures. In this framework, the key concept considered is the perception, with his facet of essential component predecessor of behavior, defined by G. Havârneanu (2015) "psychological process by which a person receives and interprets unitary and integral information about the qualities of objects and phenomena from external environment, their assessment causing a behavioral response". Practically, individual factors interact with a risky situation causing risk perception, and further assuming avoidance or risk tolerance.

A theoretical milestone also had in mind for the research methodology considered in this article is the practical guide proposed by Ropei \& Gray (2002) in which there are summarized the most common ways of distortion the perceived risk beside the objective risk, among which: most people afraid more of the risks they are aware compared to the unknown risks; most people worry more when uncertainty is higher than when they have more information; most people fear less when they risk having control feeling and fear more when consider that they have no longer control; most people fear more facing aware risks in comparison with unknown risks.

For the study of risks associated to critical infrastructure, as a model of good practice identified in the scientific literature, is notable the research (UCONN Department of Public Policy Disaster Risk Perception, Preferences, and Preparedness Project, 2011) developed in 2011 (partnership between academia and public institutions) Amy K. Donahue being principal investigator. The report drawn up in this regard depict the results of a national survey (applied to a sample of 816 people) aiming, on the one hand, investigation of risk perception and the training level of American community in order to face the disaster at the level of officials in local government, and on the other hand, US officials assessing of local attitudes and actions to prepare for limiting the effects of disasters (Figure no. $1 \mathrm{a} / \mathrm{b}$ ).
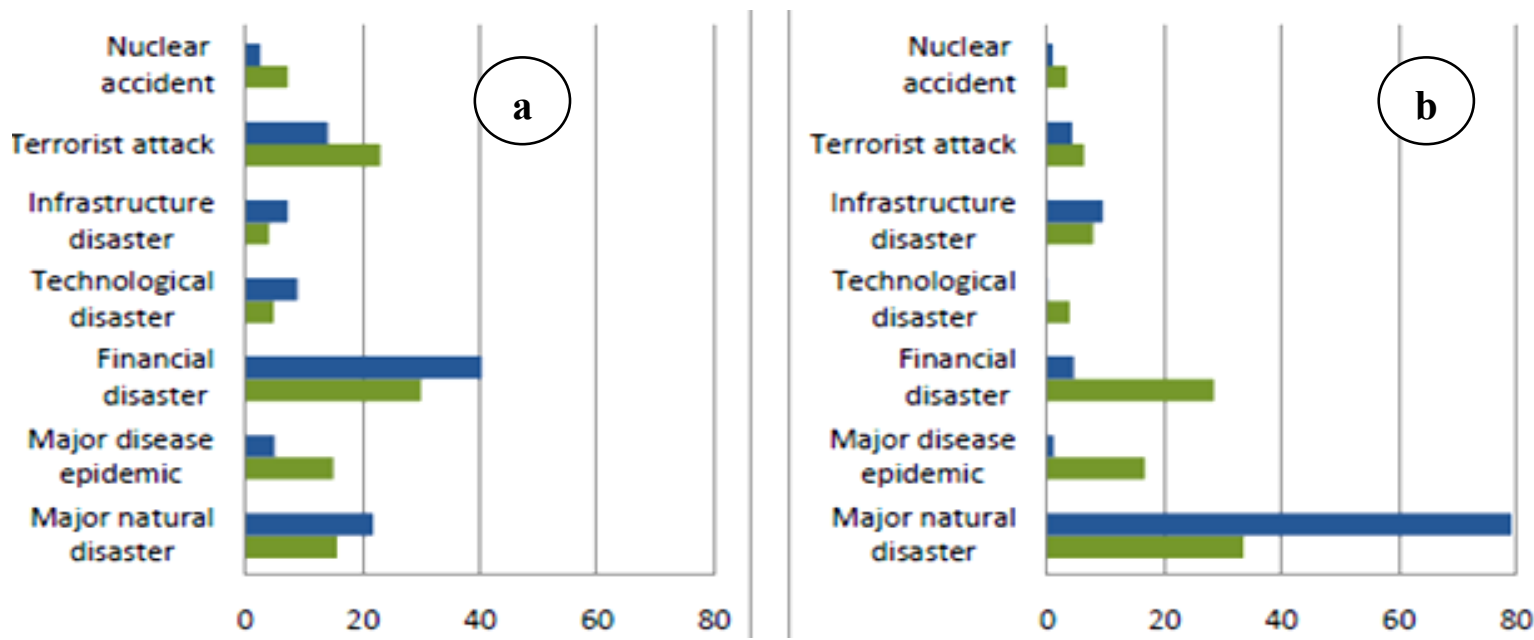

Figure no. 1 Comparative analysis on risk perception (dimensions: national-a/local-b; officials-blue/locals-green) 
The results highlighted in Figure no. 1 allows us to differentiate between the perception of risks "soft power" associated to financial sector (the highest value at national level, indicated by officials and the population, rightful result in fact if we take into account the geo-economic situation when the survey was fulfilled) and "hard power" associated with natural disasters (the highest rates indicated locally, by population and local government).

At the national level is outstanding the research conducted by the Romanian Institute for Evaluation and Strategy (IRES) on a sample of 1,519 subjects with a maximal tolerated error $2.6 \%$, the report entitled "Perceptions on national security and the incidence of some risks" (Frightened Romania. Perceptions of national security and incidence risk, 2015) published in April 2015 underlining that there were risks (considered possible) topical for the Romania: the risk of loss of artistic heritage value (66\%), the risk of armed aggression conducted by a great power $(62 \%)$, war in the region $(58 \%)$, falling stock markets $(51 \%)$, terrorism $(50 \%)$, pandemic (45\%), nuclear explosion (37\%).

Related to the subject proposed for consideration in this article, an interesting point of discussion that can be easily associated to this scientific registry belongs to renowned specialist Vasile Sebastian Dâncu, who brings into attention the new risks arising from meaning wars and image: risk related to security of information systems, risks related to image and cognitive risk. The last type of risk listed is defined in a broader context of information societies existence as influential and influenced societies by reporting to the fact that "as many means of knowledge we have, as less we know. As more open source and more scientific data we have, as more difficult is to counteract misinformation" (Dâncu, 2010). At the same time, specific aspects of critical infrastructure and subsequently, the management of civil emergencies should be analyzed from the point of view of security dimensions, especially, human security (Neag \& Pricopi, 2011).

\section{The Main Results of Research Based on Questionnaires}

The research conducted by the team of elaboration of this article is exploratory type one, carried out in order to pretest a survey which may become later, after the refinement of items, a tool for investigating specific issues of critical infrastructure at national level, through specialized institutions. The questionnaire consists of 9 items (eight of them with short multiple response and one item with open answers) and was applied in April this year on a group of 50 trainees from the program Postgraduate program "Management of Critical Infrastructure Protection" unfolded in Land Forces Academy "Nicolae Bălcescu" Sibiu.

In this case, for data processing, have been validated 45 questionnaires, the professional profile of respondents being highlighted in Figure no. 2.

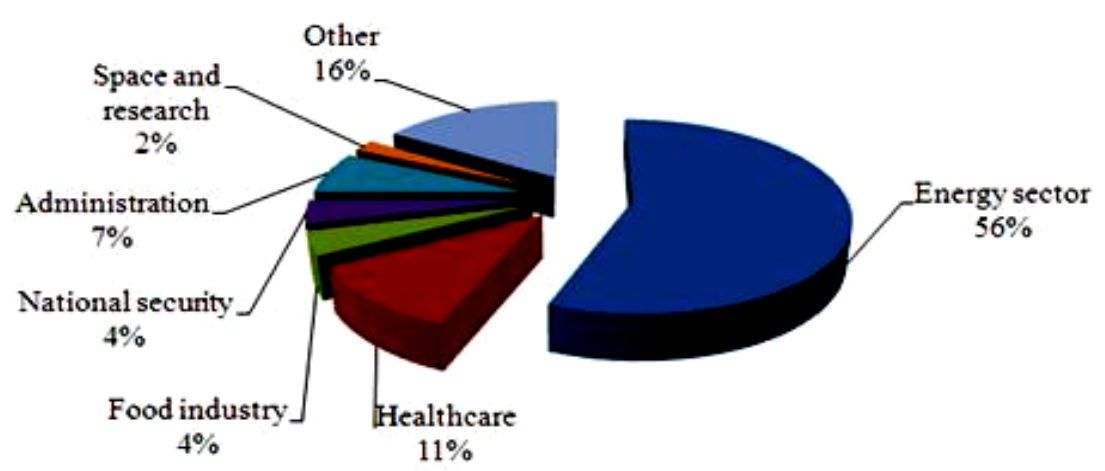

Figure no. 2 Professional profiles of participants in research based on questionnaires 
To item Q3, respondents were asked to indicate the extent of accord with the fact that measures of critical infrastructure protection should be proportionate to the associated level of risk, in relation with the core particularities of critical infrastructures, actual geopolitical situation and dynamic of required budget. Percentage distribution of responses (Figure no. 3) indicates that respondents have a mature approach, well defined, and based on understanding of the interdependence between risk, resource and protection.

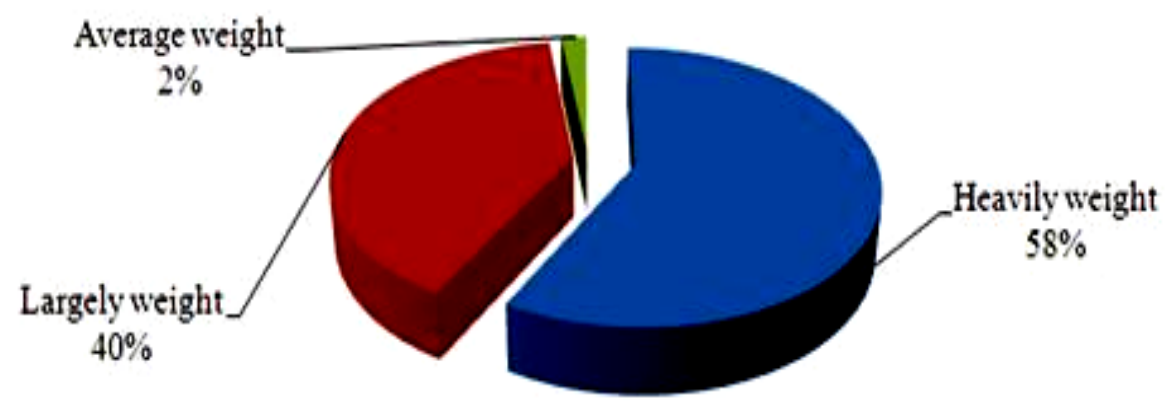

Figure no. 3 Perception of operationalizing level of critical infrastructure protection measures related to associated risk

By item Q6, the respondents were asked to assess the extent to which it must be acknowledged that in any situation can intervene human error as a destructive factor, given that the human factor plays a crucial role in critical infrastructure protection (analysis of socio-technical information, operating way, decision, etc.). Figure no. 4 shows percentage distribution of responses to this item.

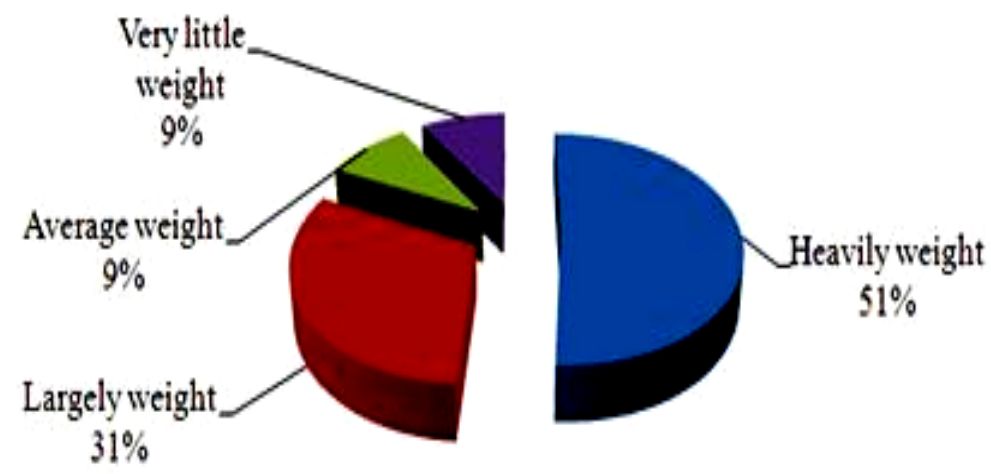

Figure no. 4 Occurring probability assessment of human error as a destructive factor in critical infrastructures

To item Q7, in relation to the national context, the respondents were asked to assess in which those sectors (Table no. 1), the activities could lead to an event (accident or disaster) with severe consequences on society. It is noted awareness of the high risk level (93\%) for nuclear and hydroelectric works and a lower level (78\%) for military installations. 
Occurring perception of a severe event in different sectors of critical infrastructure

\begin{tabular}{|c|l|c|c|}
\hline $\begin{array}{c}\text { Crt. } \\
\text { no. }\end{array}$ & \multicolumn{1}{|c|}{ Sectors of critical infrastructure } & $\begin{array}{c}\text { Cannot produce } \\
\text { a serious event }\end{array}$ & $\begin{array}{c}\text { Can produce } \\
\text { a serious event }\end{array}$ \\
\hline 1. & Oil processing facilities & $20 \%$ & $80 \%$ \\
\hline 2. & Natural gas transportation facilities & $16 \%$ & $84 \%$ \\
\hline 3. & Nuclear plant & $7 \%$ & $93 \%$ \\
\hline 4. & Hydroelectric works & $7 \%$ & $93 \%$ \\
\hline 5. & $\begin{array}{l}\text { Research institutions/producing biological } \\
\text { materials, serums, vaccines etc. }\end{array}$ & $16 \%$ & $84 \%$ \\
\hline 6. & Military installations & $22 \%$ & $78 \%$ \\
\hline
\end{tabular}

For item Q8,the respondents were asked to rate the extent to which it is accepted an economically advantageous offer, living in proximity of critical infrastructures systems, using a scale Lickert type with fivesteps, where $1=$ heavily weight and $5=$ very little weight. In order to achieve a hierarchy, the average for each set of critical infrastructure systems were compared (Figure no. 5); therefore, the higher is the system average, the fewer respondents would like to live near it, despite economically advantageous offers.

In order to deepen the analysis of data obtained through this questionnaire we correlated the respondent's answers to the above questions and we have obtained some significant correlations that create a clearer picture of the respondents' perception of the risks associated to critical infrastructure. Thus, respondents who admit to a greater extent that the human error may intervene in any situation are more aware about the fact that critical infrastructure protection measures must be proportionate to the level of risk associated $(r=0.34$, $p=0.021)$ and they believe that the factor with the greatest success in ensuring this protection would be the strategic orientation of the necessary actions $(\mathrm{r}=0.41, \mathrm{p}=0.004)$. At the same time, these respondents admit that they would accept to a lesser extent to live in the proximity of a nuclear power plant $(\mathrm{r}=-0.45, \mathrm{p}=0.002)$, a seismic area $(\mathrm{r}=-0.38, \mathrm{p}=0.0009)$ or a petrochemical complex $(\mathrm{r}=-0.29, \mathrm{p}=0.048)$. Regarding the management of critical infrastructure protection, they claim to be less concerned with issues such as legislative harmonization $(\mathrm{r}=-0.36, \mathrm{p}=0.014)$ and risk assessment $(\mathrm{r}=-0.29, \mathrm{p}=0.047)$. Respondents who admit to a lesser extent that the human error may intervene in any situation are concerned in a greater extent with the possibility of an event with serious consequences on society (accident or disaster) in the following sectors: oil processing facilities $(r=-0.30, p=0.041)$, nuclear plant $(\mathrm{r}=-0.31, \mathrm{p}=0.036)$ and hydropower facilities $(\mathrm{r}=-0.31, \mathrm{p}=0.036)$.

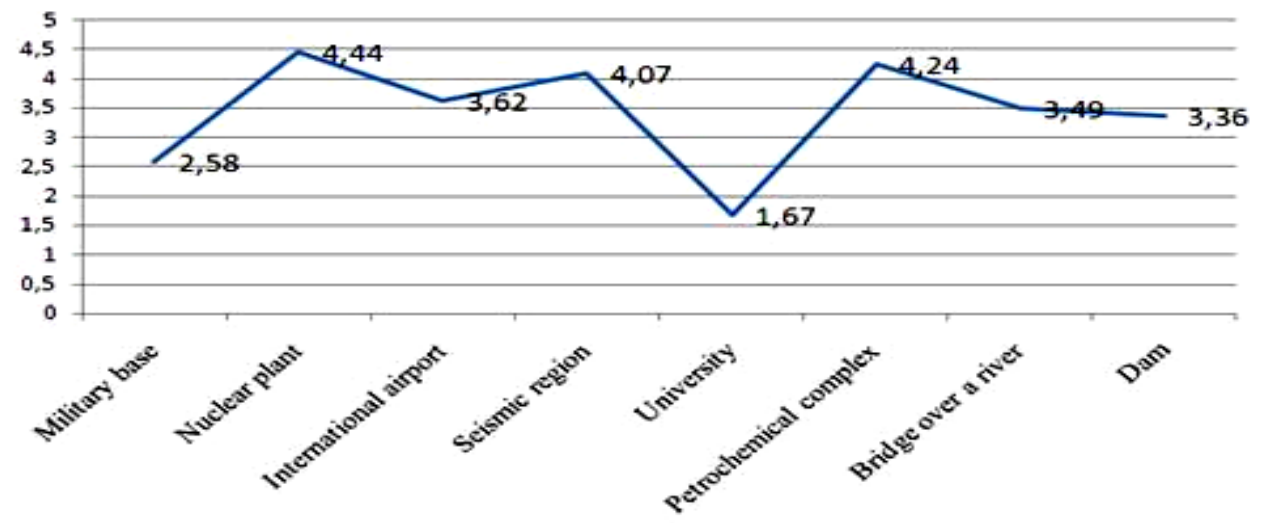

Figure no. 5 Risk perception associated with different critical infrastructure 


\section{Final Remarks}

The results indicate a high level of awareness of the main risks specific to certain sectors of critical infrastructure, which must be correlated with a good knowledge of the issue in the field, due to the fact that most of respondents are occupying positions in these sectors. Perception of the nuclear risks can be correlated with recent events (incidents or disasters) being the most serious as impact and, perhaps most publicized. Meanwhile, defense is associated with safety (see data in Table no. 1 and Figure no. 5).

We support the improvement of this instrument, an idea that will certainly be reinforced, and other institutions from the questionnaire mentioned at the beginning of the second point of the article. The final objective is to create a powerful tool of analysis that contributes to the achievement of larger nationally studies, based on public-private partnership to tackle the critical shortage of practical and theoretical studies in this area.

As a development perspective, we intend to apply this questionnaire within extensive professional groups to define it as valid measure the perception of the risks associated specialists in the field of critical infrastructure. Also, resulted data can be used to develop risk management scenarios based on mathematical models (Dinicu \& Oancea, 2014), to be considered elements of the security plans of some owners of critical infrastructure in a particular region, development direction that may deal with a more comprehensive plan, the crises (conflicts) arising from civil emergencies, all of them integrated and played on a dedicated software platform or thru combined real-constructive simulation (in terms of simulation types).

\section{Acknowledgment}

This paper has been elaborated during the sustainability period of the project entitled "Horizon 2020 - Doctoral and Postdoctoral Studies: Promoting the National Interest through Excellence, Competitiveness and Responsibility in the Field of Romanian Fundamental and Applied Scientific Research", contract number POSDRU/159/1.5/S/140106. This project was co-financed by European Social Fund through Sectoral Operational Programme for Human Resources Development 2007-2013. Investing in people!

\section{REFERENCES}

Dinicu, A. \& Oancea, R. (2014). Predictability Possibilities Based on Mathematical Models of Conflict Situations, The $10^{\text {th }}$ eLearning and Software for Education Conference eLSE 2014, vol. 1, Bucharest: National Defense University "Carol I" Publishing House, pp. 133-136.

Dâncu, V.S. (2010). Cognitive war, safety culture and risk perception. Romania and others, in G.C. Maior, A mind war, Bucureşti: Rao, p. 129.

Havârneanu, G. (2015). The risk from a psychological perspective, in Havârneanu, C. \& Havârneanu, G., (Eds.) Risk psychology, Iaşi: Polirom, p. 18.

Ropei, D. \& Gray, G. (2002). A practical guide for deciding what's really safe and what's really dangerous in the world around you, Houghton Mifflin.

Neag, M.M. \& Pricopi, M., (2011). Human Security Parameters and Indicators, International Conference Military Science Universe National Defence University "Carol I", volume 1 Security and Defense, Bucharest: National Defense University "Carol I" Publishing House, pp. 240-247.

Frightened Romania. Perceptions of national security and incidence risk (2015). Retrieved from https://www.scribd.com/doc/264485908/IRES-Perceptii-Privind-SecuritateaNationala-Si-Incidenta-Unor-Riscuri-2015-raport-de-Cercetare, accessed at 27.03.2016. 
UCONN Department of Public Policy. Disaster Risk Perception, Preferences, and Preparedness Project. (2011). Retrieved from http://Dpp.Uconn.Edu/Wp-Content/Uploads/ $\underline{\text { Sites/307/2013/11/Risk-Perceptions-And-Preparedness-Volume-2.Pdf, accessed at 11.05.2016. }}$ 